\title{
LEGAL ASPECTS OF PSYCHOTIC DISORDERS
}

\section{Osakidetza}

Mancebo-Fernández, G1 ${ }^{1}$ Paniagua-Velasco, A. ${ }^{1}$, Andrés-Rodríguez, L. ${ }^{1}$, Aymerich-Nicolàs, C. ${ }^{1}$, Blanco-Vilches, J. ${ }^{1}$, Gómez-Guimaraes, D. ${ }^{1}$, Laría-Bustillo, I. 1, Urruticoechea-García, I. 1, Martínez-Valle, A. ${ }^{1}$, Fernández-Rivas, A. ${ }^{1}$, Sesma-Pardo, E11, González-Torres, M. A. ${ }^{1}$.

${ }_{1}^{1}$ Psychiatry Department. Hospital Universitario Basurto. Osakidetza, Bilbao (Spain).

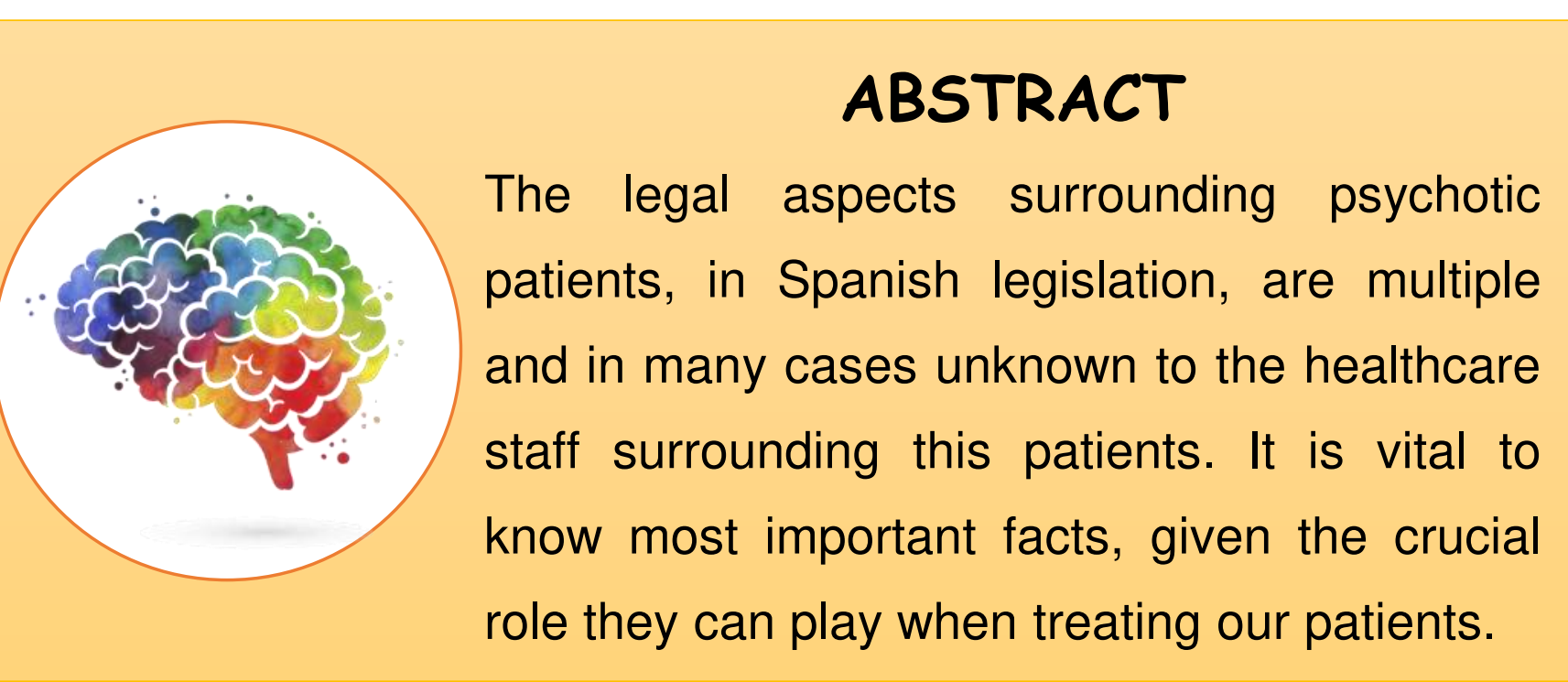

$\min$

\section{CLINICAL CASE}

A 28-year-old male, with a diagnosis of paranoid schizophrenia, who is admitted to the rehabilitation unit after relapse of his disorder to continue hospitalization by court order of a security measure consisting of a 2-year psychiatric internment imposed by the criminal court of Bilbao.

The patient lives in Spain since 2006. In 2009 he suffered a first psychotic episode in the context of treatment with levetirazetam (due to seizures). Since then, the pacient has several incomes in acute units as a result of behavioral disorders that are understood as psychotic decompensations. In addition to this clinic, the patient begins with THC consumption in this period of time.

During one of the permits of an admission the patient goes out to the street and stars in a confrontation with two gypsy people whom he hurts with a knife. Following these events and the patient being admitted, the criminal court decides to impose a security measure for the patient consisting of an involuntary psychiatric admission of 2 years

CONCLUSION:The legal aspects surrounding psychotic patients are very complex and sometimes unknown to healthcare personnel. The study of these aspects becomes a vital field when it comes to treating our patients.

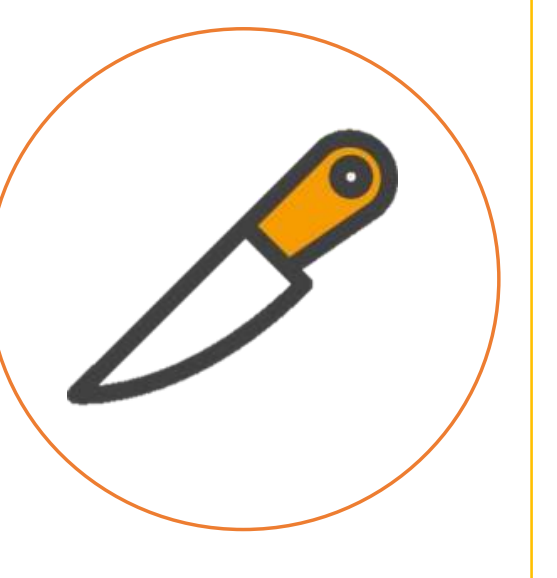

\section{METHODS}

Through the presentation of the clinical case of a 28-year-old patient diagnosed with schizophrenia, we will review the most transcendental points related with the legal aspects of the psychotic disorders.

\section{DISCUSSION}

In Spain, the Criminal Code includes a catalog of extenuating and exonerating circumstances. The application of this circumstances must be assessed and agreed by the Judge and they may result in the reduction, elimination or replacement of the legally imposed penalties.

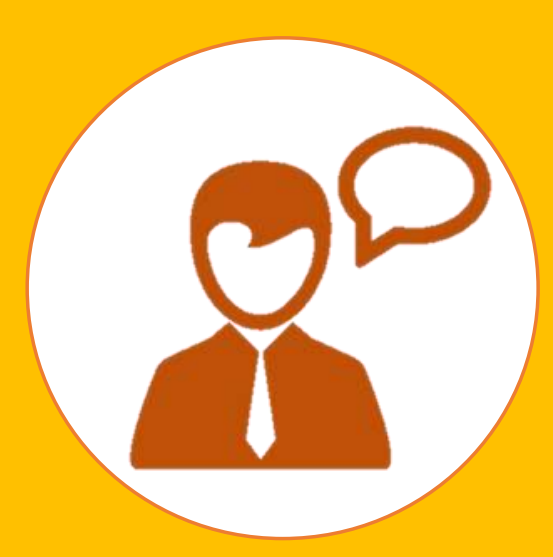

\section{EXEMPTS}

- Minority of age

- Anomalies or psychic changes mental disorder

- Transitory full intoxication

- Abstinence syndrome

- Serious changes in perception

\section{EXTENUATING}

CIRCUMSTANCES

- The previous if they are not very intense

- Passionate state, blindness, rapture.

- insuperable fear

\section{IMPUTABILITY}

1. It is the psycho-biological ability to respond to the acts that are performed.

2. Ability to understand what is done and know if it is fair or unfair.

3. Ability to act freely and be able to opt for a decision or its opposite.

$\checkmark$ It is not enough with the diagnosis of psychotic disorder to be not subject to criminal liability.

$\checkmark$ The disorder must alter the ability to understand and act.

\section{SECURITY MEASURES}

\section{Custodial Sentences}

1. The internment in a psychiatric center.

2. The internment in the center of detoxification.

3. The placement in a special educational center.
Non-Custodial Sentences Probation: Submission of the convicted person to judicial control through compliance by one or some of the following measures: The obligation to follow external medical treatment, or to undergo periodic medical control. 